\title{
Limites e possibilidades no uso de fontes históricas: batismos, inventários e relatos de viagem
}

Limits and possibilities in the use of historical sources: baptisms, inventories and travel reports

\author{
João Davi Oliveira Minuzzi* \\ jdminuzzi@gmail.com \\ Taís Giacomini Tomazi** \\ taistomazi@gmail.com
}

Resumo: Neste trabalho abordaremos algumas possibilidades de uso de fontes para pesquisas na área de História. Focaremos nossa análise em três tipos de fontes: batismos, inventários e relatos de viagem. Iremos retomar alguns textos clássicos que se utilizaram destas fontes e apontaremos caminhos que podem ser trilhados utilizando cada uma dessas através de métodos de pesquisa em História e outras áreas das Ciências Humanas. Compreendemos que o bom tratamento das fontes é um importante aspecto no trabalho do historiador, de forma que o acesso a elas deve ser facilitado e, por isso destacamos a importância de instituições como Museus e Arquivos, essenciais no processo de preservação e ampliação do conhecimento histórico. Espaços estes, onde os elementos principais da discussão a ser pretendida aqui estão guardados e disponíveis para o trabalho dos profissionais da História. Por fim, iremos expor o que temos realizado em termos de pesquisa, vindo de encontro com a perspectiva apontada ao longo deste trabalho.

Palavras-Chave: fontes históricas, trabalho metodológico, limites e possibilidades

Abstract: In this paper we discuss some usage possibilities of sources for research in the field of History. We will focus our analysis on three types of sources: baptisms, inventories and travel reports. We will resuming some classic texts with these sources and will point out ways that can be roamed using each of these through history research methods and other fields of Human Sciences. We understand that the proper treatment of the sources is an important aspect in the historian's work, so that access to them should be facilitated and thus we emphasize the importance of institutions such as Museums and Archives, essential in the preservation process and expansion of historical knowledge. These spaces, where the main elements of the discussion to be desired here, are saved and available for the work of professionals in History. Finally, we will explain what we have done in terms of research, approaching with the prospect pointed throughout this paper.

Keywords: historical sources, work methodology, limits and possibilities

\footnotetext{
* Mestrando em História pela Universidade Federal de Santa Maria (UFSM). Bolsista Capes-DS. Orientado pelo professor Luís Augusto Farinatti e coorientado por Carlos Henrique Armani.

** Mestranda em História pela Universidade Federal de Santa Maria (UFSM). Orientada pelo professor Luís Augusto Farinatti e co-orientada por João Davi Oliveira Minuzzi
} 


\section{Introdução}

Neste artigo iremos abordar algumas questões referentes a fontes de pesquisa para a área de História, sendo este, um artigo de revisão bibliográfica a respeito do uso metodológico das seguintes fontes: os inventários post-mortem, os registros de batismo e os relatos de viagem, estas são as principais fontes de nossas pesquisas. O uso destas fontes também tem sido recorrente nos trabalhos desenvolvidos pela historiografia e por nossos colegas do Núcleo de estudos dos oitocentos (NEXIX), que é o grupo de pesquisa do qual participamos sob orientação do professor Luís AugustoEblingFarinatti.

Buscamos, neste texto, apontar alguns trabalhos relevantes da historiografia que pensam no uso destas fontes metodologicamente. Esta breve revisão realizada aqui pode propiciar para aqueles que não têm contato com este tipo de fonte uma noção básica do que pode ser desenvolvido a partir delas. Iremos buscar dar destaque para as possibilidades de trabalhos a serem desenvolvidas, pois há uma grande variedade de assuntos a serem explorados a partir de diferentes enfoques e posicionamentos. Não deixaremos de comentar as dificuldades e cuidados que cada uma dessas fontes necessita e apresenta.

Nosso enfoque para pensar este artigo é o espaço platino do século XIX, especialmente o território que compreendia a região onde hoje identificamos o município de Alegrete, mas também os demais municípios da fronteira oeste-sul, os quais pertenciam a jurisprudência da referida cidade, como visto no mapa 1.

Utilizamos a historiografia que centra no estudo desta região e época para discutirmos a utilização destas fontes. Porém, temos consciência de que estes tipos de fontes podem ser encontrados por todo o Brasil e que as mesmas têm sido trabalhadas para outros recor-

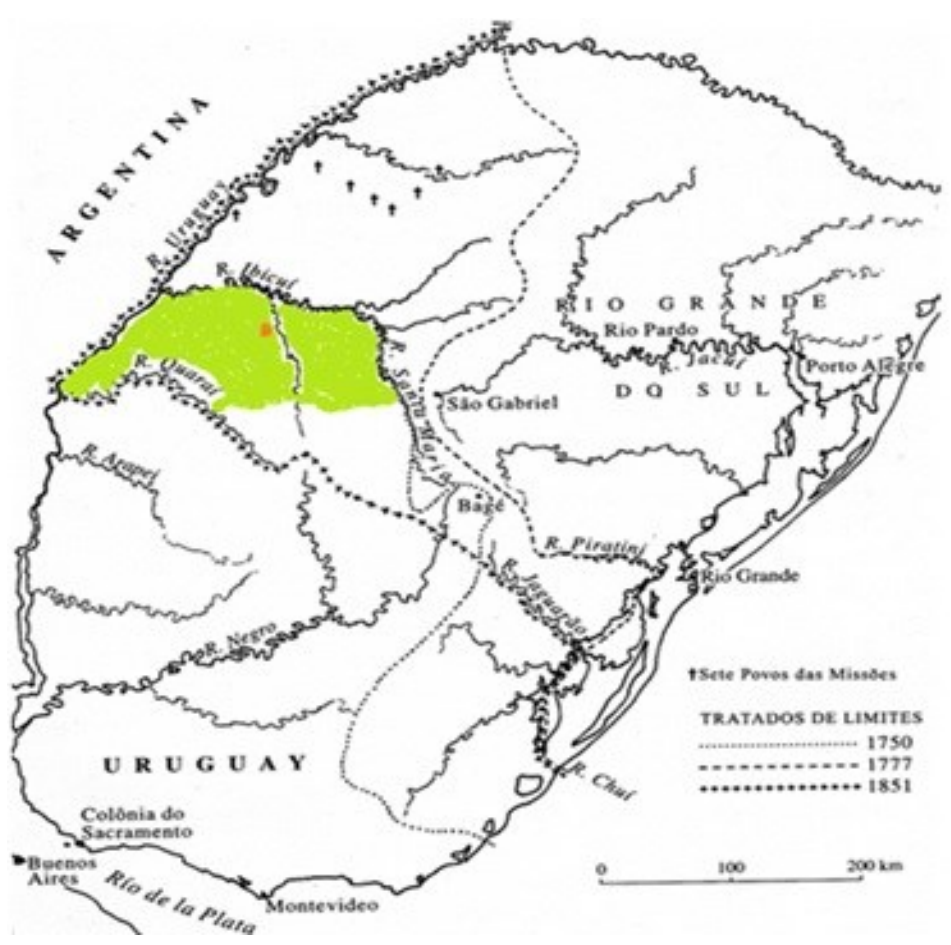

Mapa 1-Capela de Alegrete, jurisdição aproximada (18171845).

Fonte: FARINATTI, Luís Augusto Ebling. Confins Meridionais: famílias de elite e sociedade agrária na fronteira sul do Brasil (1825 - 1865). Santa Maria: Editora da UFSM, 2010 (por FELIZARDO, Julia Netto. Evolução Administrativa do RS. Porto Alegre: Governo do RS, s/d) [grifo nosso].

tes espaço-temporais, ou seja, nada impede de que novos trabalhos sejam realizados pensando outras realidades através da utilização das fontes aqui exploradas. Dentro das possibilidades e das influências que recebemos, buscaremos iniciar o diálogo com a historiografia de outras regiões e períodos.

Pretendemos que este artigo propicie o início de uma reflexão metodológica sobre estas fontes e que mais trabalhos possam partir desta iniciativa, especialmente aqueles que procuram novas perspectivas e usos para documentos, sejam os aqui apresentados ou quaisquer outros. Destacamos também a importância de locais de salvaguarda destas fontes, como arquivos, bibliotecas, museus e demais locais de memória, os quais garantem acesso e manutenção destas fontes. Por isto, este trabalho também é uma tentativa de salientar a importância destes locais para os estudos sobre o nosso passado, desempenhando valorosa função em nossa sociedade e devendo, por isto, uma maior atenção dos 
órgãos públicos para a conservação e ampliação de espaços de pesquisa como estes.

\section{A graça de Deus e os registros de batismos}

"Desde há muito, os registros paroquiais foram percebidos como documentação privilegiada para dar suporte a investigações sobre populações" (HAMEISTER, 2013, p. 2).

A diversidade no uso de fontes eclesiásticas nos apresenta um leque de possibilidades que contribuem na exploração de elementos de pesquisa como, por exemplo, a questão da legitimidade escrava. Um dos aspectos se dá na análise da problemática dos filhos de escravos, além da possibilidade do estudo das famílias escravas em suas diversidades e especificidades. Ainda no campo da legitimidade, temos as mães solteiras, que podem demonstrar alguns elementos sociais, as relações entre as mulheres que não estabeleciam laços formais de relacionamentos e a segurança que o batismo delegava aos filhos destas em caso de sua falta e disso advém a relação estabelecida no título deste subiten "a graça de Deus e os registros de batismos" a qual relaciona a importância da questão religiosa que se constrói da salvação a partir do batismo e da necessidade prática de registrar a sociedade já que não havia ainda o registro cartorial, por exemplo, dos nascimentos e casamentos.

Procuramos no decorrer deste texto analisar estas fontes - neste caso o uso de batismos do século XIX, e que foram realizados na capela de Alegrete - buscando compreender as possibilidades de trabalho que estas apresentam. Sem deixar de perceber o contexto em que foram produzidas, já que estamos a tratar de uma zona de fronteira onde constantes conflitos e problemas de infraestrutura e de locomoção implicam em diferenças marcantes se comparado à realidade de centros urbanos do mesmo período. Righi e Tomazi (2014) apontam que estes indivíduos eram batizados em grande parte antes do primeiro ano e cerca de $30 \%$ destes até os 03 meses de idade, o que demonstra que a fonte pode dizer mais do que apenas uma alocação de informações. A análise intrínseca da produção da fonte também é um elemento que se torna interessante.

No caso da Capela de Alegrete, (ou a Capela de Nossa Senhora Aparecida do Alegrete, que procuramos demonstrar o espaço aproximado de sua jurisdição no Mapa 1), é possível verificar a importância da existência deste tipo de prática religiosa na perspectiva de uma manutenção do território luso brasileiro e para a continuidade de relações sociais e espirituais daqueles grupos que residiam e iam se instalando na região oeste.

Além do incentivo à produção de gêneros alimentícios e principalmente a criação de gado, os lusobrasileiros instalaram pontos e aparelhos religiosos de forma a se estabelecer e atender religiosamente a população que estava naquele território e as populações que ali iam chegando. Por isso outra possibilidade de trabalho com estas fontes é a ligada aos movimentos migratórios de grupos que se deslocam pela região oeste, alguns em saída das antigas regiões missioneiras outros para o interior da província e vice versa.

Para compreendermos a importância da instalação deste tipo de artefato, no caso deste trabalho e das pesquisas relacionadas, a Capela de Alegrete e este tipo de fonte, há que se prensar na complexidade social que abarca o fato de se estabelecer de forma oficial um suporte religioso para a população, e também a presença da Igreja Católica nas possessões do império, segundo o texto de Matheus (2013). Este aponta que o estabelecimento de capelas tinha como função agir tal como um mecanismo de peso das autoridades sendo uma marca da sua representatividade naquele território, já que a "migração populacional e a ideia de uma sociedade temente a Igreja e que necessitava da atenção de um pároco para proferir missas, batizar e casar a população, 
de modo que a mesma pudesse viver sob os desígnios de Deus" (RIGHI; TOMAZI, 2014, p. 1736).

Destacamos desta forma a importância deste tipo de fontes eclesiais para a pesquisa histórica o que também evidencia a consistência das pesquisas que as utilizam para a construção de trabalhos acerca de diversas sociedades, grupos, temáticas e perspectivas, não só no Brasil, mas também de todo território iberoamericano. Assim como os batismos, outros registros eclesiásticos podem ser utilizados, tais como os registros de casamento e de óbito, entre outros. O emprego destas fontes vem trazendo contribuições para o estudo de relações sociais, das características culturais e das alianças políticas que se estabeleciam no território de conflito da fronteira oeste.

É possível trabalhar com uma história que enfoca e procura compreender as hierarquias sociais que constituem a sociedade, visto que a mesma é baseada em diferenças construídas socialmente e que acabam por serem naturalizadas enquanto tais, ou também investigando a mobilidade social dos sujeitos históricos em seus contextos (FARINATTI, 2012). Além das hierarquias sociais e mobilidade social, a variação da condição jurídica dos sujeitos e a prática da escravidão também podem constituir elementos de análise. Nesse sentido, temos as pesquisas desenvolvidas por Luís Augusto Farinatti, que fazem uso dos registros paróquias da Capela de Alegrete, durante boa parte século XIX, no qual analisa estas mesmas fontes, com relação aos compadrios no estabelecimento de relações entre potentados militares na primeira parte do XIX

Max Ribeiro (2013) também é um autor que pode ser utilizado para se analisar o uso de fontes eclesiais. O historiador trabalhou com a questão indígena, utilizando entre os anos de 1801 a 1834 os registros batismais da Capela de Santa Maria. Não usou apenas esta fonte, procurou estabelecer um cruzamento, por exemplo, com registros militares.

Assim, o ato do batismo se liga aos elementos religiosos que lhe são essenciais, mas também podemos trazer à tona as transformações sociais, econômicas e políticas ocorridas ao longo da metade do século XIX. Martha Hameister(2013) evidencia a questão dos limites e possibilidades da utilização dos batismos, e ainda possibilita uma análise destes elementos mais completa, já que sabemos que o ato de batizar é identificado como uma prática que ultrapassava limites, interligando o mundo espiritual e o material. E isto, muito em função das relações sociais e as redes construídas em razão do ato religioso, as quais deveriam ser preservadas e cuidadas por toda vida dos indivíduos.

Estes textos tornam possível a visualização de um processo histórico maior e mais complexo que para a análise das fontes torna-se necessário conhecer já que elas "estão impregnados pelos interesses de quem os construiu, sejam esses agentes individuais ou coletivos" (HAMEISTER, 2013, p. 3), logo que são produzidos por pessoas que fazem parte de um contexto especifico e que têm sua própria ação por sobre os documentos (não fazendo referencia a documentos oficias, mas sim todo tipo de documentação escrita) que produzem.

Outra autora que também trabalha com a fonte eclesial do batismo, é Lott (2006), que nos demonstra a transformação deste tipo de documentação, e como isso é importante no tratamento da mesma. O ponto principal de suas ponderações é a realização imprescindível da crítica e a tabulação (além da posterior análise) da mesma levando em conta os aspectos teóricos e metodológicos do trabalho empírico. Antes de seguir, apenas uma questão essencial apontada por Hameister, que se refere à sempre necessidade da atenção ao tratar das fontes, de forma que "não somente no uso dessa, mas de qualquer outra documentação como fonte de suas 
pesquisas: o uso que ele faz da documentação normalmente extrapola as intenções de quem - coletivo ou individual - procedeu tais registros documentais" (HAMEISTER, 2012, p. 6).

Dando prosseguimento, outra possibilidade de pesquisa que ficou em aberto e que pode se tornar uma outra perspectiva de análise é a importância social relacionada ao casamento institucionalizado pela religião na manutenção dos poderes, pode ser a partir do apadrinhamento de bastardos. Mas também não há como esquecer a questão dos amasiamentos, mais difíceis de encontrar, porém com certo rigor e insistência estão presentes nas entrelinhas das fontes, talvez a mudança da escala de análise seja um ponto forte para a continuidade de uma pesquisa de caráter específico e tematicamente essencial. Todos estes aspectos podem pode falar, apontar ou demonstrar muitos elementos da vida privada das mulheres, crianças e homens da fronteira ou qualquer outro espaço-tempo de pesquisa.

A principal metodologia utilizada na análise destas fontes (FARINATTI, 2009; RIGHI; TOMAZI, 2014) foi o a metodologia serial, pois como afirma Fragoso e Pitzer (1988) para se pode utilizar este tipo de fonte na metodologia serial é necessária à sua repetição temporal (batismos eram e são realizados constantemente), padronização (existe um padrão para a escrita das informações do batizado) e uma quantidade razoável que se dá muito em função destes elementos anteriores. Para se conseguir trabalhar pragmaticamente com os dados geralmente os alocam em locais de armazenamento, no caso do NEXIX, foi o programa Excel for Windows, o qual possibilita o estabelecimento de campos de pesquisa, organização dos dados e uma posterior tabulação dos mesmos e a filtragem de elementos necessários para cada análise. Um dos pontos desfavorá- veis no uso deste programa é a pouca facilidade de cruzamento de dados com outras fontes.

A abordagem metodológica micronominal, advinda da proposta de Ginzburg "O nome e o como" e o "paradigma indiciário" podem ser de grande importância quando se usa fonte nominal e que contenha informações como parentalidade, localidade de nascimento, parentescos, cor e condição jurídica. Além disso, os registros de batismos são ótimos aportes para o apoio no cruzamento de outras fontes, a partir das relações de compadrio, por exemplo.

\section{O resultado de uma vida: inventários post mortem}

"A diversidade dos bens avaliados e as histórias que se pode contar a partir dos próprios inventários é muito rica" (VARGAS, 2013, p. 187).

Os inventários post mortem, são ações judiciais realizadas em razão da morte de um indivíduo. Este deveria possuir bens a serem partilhados, além de dívidas ativas ou passivas ${ }^{1}$. As partes de um inventário que geralmente são elencadas nas pesquisas e são mais utilizadas pelos historiadores são: a) Abertura do Inventário; b) Descrição e avaliação dos bens; c) Documentos comprobatórios da avaliação e de dívidas; d) Partilha dos bens. Esta organização padronizada das informações dá um caráter confiável ao documento, quando passível do trabalho de seriação, por exemplo. Todos estes elementos que Fragoso e Pitzer (1988) apresentam acabam demonstrando como a análise destas fontes podem ser interessantes se é tomado o cuidado metodológico de crítica ao documento e o esforço do pesquisador em estar atento aos detalhes possíveis.

\footnotetext{
${ }^{1}$ As dívidas passivas são aquelas que outrem possuíam em haver para com o inventariado e as ativas eram quando o mesmo tinha a pagar, em crédito, com outros indivíduos.
} 
Como a historiografia apresenta o trabalho com inventários post mortem já é consolidado e se pode traçar panoramas bem sólidos sobre suas possibilidades e limites $^{2}$. Farinatti (2010) apontou em seu trabalho com a elite criadora de gado de Alegrete as potencialidades da fonte, mas a partir deste trabalho também podemos ir além. Estudando elementos relacionados a outros grupos, como os peões e escravos. Estes, não são visíveis na hegemonia de dados comumente vistos e contidos na fonte, mas que podem ser encontrados em função da metodologia empregada e das perguntas.

Em relação ao comércio, que é uma das pesquisas que está sendo finalizada neste período, os inventários dão um panorama do que se consumia em vida, diferentemente do que havia nas listas de compras e das vendas. Já que as listas se mostram relacionadas em boa parte, mas não toda, a bens cotidianos mais alimentícios que bens de uso. A partir dos bens móveis dos inventários é possível perceber em uma escala de tempo maior, as transformações desta sociedade. Ao aliarmos isso com outras pesquisas, a questão do contrabando se mostra interessante para compreender o contexto e as relações fronteiriças estabelecidas pelos indivíduos daquele período e local, como Thompson Flores (2007) e outros autores (VOLKMER, 2013; BLEIL DE SOUZA, 2009) apontam como diretrizes importantes na construção da história desta província.

Mas há também os limites que a fonte apresenta. Já que esta é produzida no momento em que algum familiar falece, pois também, segundo Vargas (2013),

os inventários post mortem não são suficientes para dar conta deste tipo de pesquisa, pois, muitas vezes, os charqueadores faleciam numa idade mais avançada de suas vidas, quando já haviam abandonado as atividades mercantis, buscando uma condição econômica mais segura (VARGAS, 2013, p. 126).
Desta forma, muitos bens poderiam já ter sido doados aos filhos e não constarem na fonte, isso limita a análise, mas o cruzamento de dados pode contribuir neste sentido. Assim, é possível trabalhar com a ideia de grupos diferenciados. Outro limite do uso de inventários é a sua própria produção. Já que há uma questão chave: só fariam inventários aqueles indivíduos que possuíssem algum bem passível de documentação, ou seja, muitas pessoas ficavam de fora da análise já que não possuíam bens importantes na lógica da época ou mesmo não queriam pagar os tramites do processo. Muitos inventários acabam sendo arquivados sem que terminassem as etapas em função dessa não continuidade.

Outra apreciação possível e relacionada a questões familiares propriamente ditas são as disputas entre irmãos e os casamentos feitos para a criação de alianças que podem causar brigas internas. A partir de uma análise qualitativa seria possível trabalhar com estes elementos, já que esta temática ainda está em aberto na historiografia rio grandense. E seguindo a esta linha familiar, podemos indicar ainda a questão da tríade família, poder, dominação podendo esta ser substituída pela hierarquização. Isso pode ser demonstrado por Farinatti (2009), já que

Os inventários post mortem, ainda que também abrigassem fraudes, são mais confiáveis do que as listas de qualificação no que tange à possibilidade de analisar patrimônios, de perceber a concentração de fortunas e recursos porque envolvem interesses contraditórios dos herdeiros que, em tese, exerceriam uma fiscalização sobre as irregularidades do processo (FARINATTI, 2009, p. 12).

A partir dos inventários e das disputas entre indivíduos ligados a parentalidade oficial (dada no casamento legítimo), mas sem perder de vista os problemas

\footnotetext{
${ }^{2}$ Verificar FARINATTI, 2010; TOMAZI, 2015 e VARGAS, 2013 para trabalhos utilizando inventários post mortem.
} 
relacionados aos filhos fora do casamento, não aceitação de um componente novo, entre outras possibilidades. Estas aliadas a outras fontes como criminais e eclesiásticas (tal como o já citado registro de batismo) podem abrir um panorama social ainda pouco explorado.

Ao nos propormos a traçar os limites e possibilidades da pesquisa com fontes diversas, os inventários post mortem aliados aos relatos de viajem são mais um ponto chave de pesquisa. Já que ao se estabelecerem relações históricas entre os dados encontrados numa e outra fonte, os relatos de viajantes podem proporcionar um contraponto com o que se encontra nos inventários. $\mathrm{Na}$ fronteira de Buenos Aires, Laura Cabrejas (2000) faz muito bem esta análise e é uma autora chave quando se fala da questão das moradias e do cotidiano daquelas populações.

A questão dos relatos de viagem será desenvolvida com mais atenção no próximo item, mas de antemão Eliane Fleck (2006) pode nos dar um panorama, pois ao trabalhar com os viajantes no período colonial contribui na elaboração de elementos interessantes para o Rio Grande do Sul que também é palco para as discussões específicas deste trabalho. Uma questão final, mas não menos interessante é que, apesar de estarmos trabalhando focados em um período e espaço específico, a proposição maior se dá no sentido de apresentar as possibilidades de uso das fontes históricas, em diversas outras temáticas, metodologias e relações tempo/ espaço.

Antes de partirmos para os viajantes, é importante explicitar alguns pontos sobre a micro história, abordagem metodológica que muito se relaciona com as pesquisas desenvolvidas pelo NEXIX. Para entender -se o que se propõem à micro história, Revel aponta que "retomando uma metáfora que foi muito utilizada nos últimos anos, variar a focalização de um objeto não é unicamente aumentar ou diminuir seu tamanho no visor, e sim modificar sua forma e sua trama" (REVEL, 2010, p. 438). E desta forma, muitos dos trabalhos tem sido desenvolvidos buscando esta abordagem, que possibilita outra percepção a respeito da realidade, fugindo de esquemas mais ampliados, que ordinariamente estão envoltos na fumaça da generalidade (TOMAZI, 2015).

\section{A partir da percepção do outro: os relatos de viagem}

"A literatura de viagem constitui-se numa das principais fontes para a historiografia, sendo também amplamente utilizada em trabalhos de literatura, sociologia e antropologia. Deve-se, sempre, considerar que as descrições e informações constantes nesses relatos constituem, na verdade, representações, reivindicações da realidade, produzidas com base nas visões de mundo de viajantes que incidem sobre a feitura e transformações historiográfica de uma memória" (FLECK, 2006, p. 274).

Os relatos de viagem são fontes muito utilizadas pela historiografia e bastante variadas em forma e conteúdo, porém pouco definidas e teorizadas pela historiografia. O historiador Temístocles Cezar define-os como "um gênero literário sem lei" e que "apesar de sua tradição ser bem estabelecida e sua leitura atravessar o tempo, este tipo de escrita continua avesso a debates teóricos" (CEZAR, 2010, p. 28), servindo a diversos propósitos na área de História. Devido à capacidade de estes relatos abarcarem diversos aspectos da vida humana os pesquisadores têm utilizado influências muito distintas para pensar o uso desta fonte e ainda carecemos de trabalhos que discutam de forma mais densa e geral estas questões do ponto de vista teóricometodológico. ${ }^{3}$

\footnotetext{
${ }^{3}$ Como é o caso do livro "Relatos de viagem como fontes à história", de Núncia Constantino (2012) e de outras contribuições de pesquisadores que tem trabalhado com o tema, mas que ainda precisam se consolidar como referências para a área.
} 
Os relatos de viagem são muito diversos, pois possuem uma grande liberdade de estilo de escrita, onde a vontade do viajante predomina e não existe formalidade para serem seguidas. Devido a esta questão, cada relato se mostra único e, por vezes, difícil de agrupá-lo com outros relatos que podem abranger diários pessoais ou relatórios de viagem, dependendo do ponto de vista do estudioso que os define. Não há uma classificação tão restrita do que é ou não um relato de viagem, porém existe uma concordância de que os relatos de diplomatas, emissários, naturalistas ou qualquer tipo de viajante - estrangeiro ou não - sobre um local se constituem como relatos de viagem.

O compendio organizado por Núncia Constantino é obra de grande potencial para as pesquisas que utilizem os relatos de viagem como fonte histórica. A questão da "análise textual discursiva" pode ser um aporte metodológico consistente já que ao trabalhar com a questão da análise atenta da fonte pode traçar o caminho entre as questões de interlocução do empírico juntamente ao teórico. Isto, já que os textos escritos pelos viajantes sejam nacionais ou estrangeiros não são essenciais apenas para aqueles que hoje pesquisam os locais pelos quais estes passaram, bem como torna-se importante para seus locais de origem, apontando, por exemplo, a transformação ao longo do tempo da visão do outro. Além disso compreender contextualmente e metodologicamente os relatos de viagem perpassam as referências dos principais nomes, como Tzevetan Todorov, a partir das relações entre o que chega e os estabelecidos além das proposições complexas mas interessantes de François Hartog $(2014)^{4}$, ao trabalhar com a questão dos relatos de si, e Norbert Elias com a ideia do estabelecido e do outsider, o que pode tornar a análise mais minuciosa ainda.
Alguns destes documentos tomam forma de diário contendo anotações cotidianas, outros são comentários e observações compiladas ao longo de anos que resumem o olhar do viajante durante um longo período de tempo em um local. Um exemplo de relato que resume a experiência de anos de viagem é o de Nicolau Dreys(1990), um comerciante que passa a morar na região platina e vem a escrever um relato sobre sua estada na região após dez anos vivendo ali, sendo publicado no ano de 1839.

Esta diferença, entre um diário que reúne memórias frescas e um compilado que puxa da memória lembranças de muitos anos, deve ser observada pelo historiador e levada em consideração na hora da sua análise, pois cada um privilegia algo diferente e a questão da memória é aqui muito importante. Por isto, trabalhos que discutam memória e história oral podem dar auxílio para o historiador pensar sua fonte. Nossa sugestão para este espectro é o contato com os textos de Bosi (1999), Halbwachs (2004) e Schama (1996). Estes dois últimos autores enfatizam a influência da sociedade e da natureza, respectivamente, sobre a constituição da memória. Já Ecléa Bosi (1999) trata das questões da memória nas fontes orais, que são muito diferentes dos relatos de viagem, mas suas constatações ainda assim podem ser úteis. Não só estes como outros textos podem vir a colaborar para um trabalho que vise pensar a questão da memória influenciando as informações presentes neste tipo de fonte histórica.

Também se deve ter cuidado ao ler os relatos, pois o que eles retratam nem sempre é uma verdade ou então mostram apenas um ponto de vista, o que por si só é interessante. Há "uma intenção de verdade no texto" (CEZAR, 2010, p.29) e uma tentativa daqueles indi-

${ }^{4}$ Para mais informações ver HARTOG, François. O espelho de Heródoto: ensaio sobre a representação do outro. Tradução de Jacyntho Lins Brandão. Ed. 2, Belo Horizonte: Editora UFSM, 2014 e TODOROV, Tzvetan a, "As estruturas narrativas" ou "A conquista da América". 
víduos relatarem fielmente através do texto aquilo que vivenciaram. E não apenas o texto é uma forma de se expressar, em certos relatos, existem imagens que compõe o relato, necessitando serem incorporadas na análise, como aponta Kury (2001) ao abordar a produção de Carl von Martius, que excursionou pelo Brasil no século XIX. "A iconografia e os relatos de viagem buscam, assim, descrever de modo exaustivo e profundo os diversos elementos que compõe cada lugar" (KURY, 2001, p.870), por isto, a análise conjunta do elemento textual e iconográfico pode propiciar uma compreensão mais rica sobre o tema estudado.

A história cultural tem se preocupado em utilizar os relatos de viagem, pois eles muitas vezes trazem elementos detalhados sobre assuntos do cotidiano de um período. Por exemplo, os antigos cronistas, exploradores e naturalistas, estavam preocupados em "reconhecer, identificar, descrever e classificar sistematicamente as espécies vegetais e animais" (CAMARGO, 2002, p. 89) encontradas nas regiões percorridas por eles, mas não deixaram de atentar para o modo de vida das pessoas que habitavam terras tão distantes e que possuíam costumes, hábitos, objetos e uma relação com as coisas e o meio diferentes daquelas com as quais estavam acostumados. Assim, os relatos de viagem, propiciam estudos que possam tratar de uma infinidade de temas como alimentação, moradia, relação com a natureza, relações sociais, política, guerra, produção agrária e econômica. Nem sempre o relato escolhido oferecerá uma gama tão profícua de assuntos e quase sempre apresentará informações esparsas e curtas sobre o que se está procurando. Por isso, pode ser interessante juntar uma quantidade maior de relatos que estejam em um recorte espaço-temporal próximo, o que possibilita a comparação das ideias de cada autor ou então das situações vivenciadas.
Seja qual for o tema pesquisado, é importante ter em mente que os relatos são uma parcela do que foi vivido, se baseando na percepção do viajante e do ponto de vista dele e talvez da opinião de outras pessoas que ele venha a dar espaço em seu texto, como acompanhantes de viagem, anfitriões ou pessoas com a qual tenha convivido ao longo de sua jornada. Pelo fato do relato ser fruto de sua percepção, o que podemos analisar é uma mistura de sensações recebidas pelo sentido, ou seja, não são apenas as coisas que o viajante viu, mas aquelas que tocou, cheirou, ouviu e comeu.

Nesta perspectiva, é importante que o historiador compreenda o espaço em que o viajante se encontrava e todas as coisas com as quais ele interagiu. Os objetos, por vezes, são tão banais que acabam escapando da nossa percepção diária, estamos tão acostumados com elas que acabamos não refletindo sua presença e sua influência no cotidiano, porém os viajantes possuem um olhar de fora que ressalta o uso, a presença ou a ausência de certas coisas. Estudos sobre o espaço e as coisas, como os trabalhos de Olsen (2003) e Jerram (2013), podem auxiliar a pensar na influência dos objetos na vida humana e na nossa ação sobre os mesmos. Pensar a partir desta perspectiva pode gerar olhares novos sobre este tipo de fonte e trazer à tona a contribuição que estes viajantes tiveram ao apontar estas coisas que geralmente nos são tomadas como banalidades, mas que moldam a nossa existência. Estudos ambientais e sobre a cultura material partindo dos relatos de viagem podem considerar estes elementos na sua análise.

A análise dos relatos de viajantes deve levar em conta os referenciais dos seus escritores para compreender quais os sentidos no emprego de certas palavras, pois certos adjetivos podem indicar posições do viajante perante o lugar em que ele está contribuindo com uma exaltação de certas características ou reforçando 
representações negativas sobre algo. Segundo Moreira (2009) certas palavras podem demonstrar insatisfações ou desconfortos perante condições experimentadas e certas colocações dentro dos relatos servem para justificar ações buscando tentativas para explicar inferioridades de povos e culturas perante outros, na visão do escritor do relato. Assim, estudos que se aproximem da história das ideias, da Literatura e da área da linguagem podem ser importantes para compreender melhor as visões do viajante estudado.

Para o estudo geral dos relatos de viagem, nossa indicação é o texto de Mary Louise Pratt (1999), que trabalha com os relatos de naturalistas, fazendo ligações entre os contextos europeus e os contextos latinoamericanos encontrados durante as viagens destes naturalistas. No que se refere a este tipo de relato em específico, a contribuição com a história ambiental pode ser muito rica, pois estes viajantes focam seus relatos no mundo natural e na relação deste com a sociedade. Neste sentido, diversos autores têm apontado a importância dos relatos no estudo da natureza e da História e pesquisado sobre o assunto como Amaral (2003), Drummond (1991), Minuzzi (2014, 2015), Kury (2001; 2003) e Peixoto $(2010 ; 2015)$. Estes autores apontam que os relatos oferecem um material riquíssimo para a compreensão da relação das sociedades com a natureza no passado, e podem apontar elementos que ilustrem como uma região era antigamente, quais usos políticos se fazia da natureza, até onde o ambiente afetava as relações das pessoas em sua comunidade ou na relação entre diferentes Estados Nacionais, etc. Os relatos de viagem se apresentam como fontes muito diversas, ricas e que possibilitam olhares diversos e respostas diversas dependendo das perguntas a serem feitas pelo historiador. Eles contêm muitas pistas sobre o cotidiano do passado e geralmente nos apresentam um texto cheio de descobertas que enriquecem nosso olhar sobre o que ocorreu em tempos atrás. Por outro lado, esta fonte ain- da carece de um trabalho teórico-metodológico mais detalhado e que abarque toda sua complexidade, e apesar de existir alguns trabalhos muito bons, eles não se propõem a discutir muito as características, formas de uso e limites deste tipo de fonte, focando-se mais em sua análise e recebendo influências teóricas das mais diversas áreas, como a Biologia, a Literatura e o Jornalismo. Assim, se mostra um desafio para o futuro, a elaboração de um trabalho que discuta de forma mais intensa estas questões e possa juntar todos os esforços e influências já recebidas.

\section{Algumas discussões finais}

Sobre a questão das fontes, há ainda que se apresentar alguns elementos percebidos como essenciais neste processo de construção e desenvolvimento do NEXIX. Uma delas é em alguns casos, a dificuldade de acesso das fontes, em função de alguns arquivos não disponibilizarem seus acervos para os pesquisadores. Isso pode se dar em razão de diversos pontos, um deles se relaciona com a questão de não haver uma organização arquivística dos documentos, outra por alguns destes serem de cunho religioso, o que em alguns momentos causou impedimentos procedimentais.

Há uma importância em se discutir e trabalhar com as problemáticas metodológicas e de acesso as fontes, já que alguns locais de armazenamento de documentos fecham suas portas ao pesquisador, por isso o incentivo aos locais de salvaguarda destes a fim de ampliar as possibilidades de pesquisa, já que o reconhecimento pode ser um ponto interessante. Outro elemento nesse sentido é valorizar a importância do funcionamento de locais como arquivos, museus, locais de memória e outros, sejam eles públicos ou privados. Para que se possa promover a pesquisa histórica de forma mais consistente e que seja eficiente enquanto trabalho teórico metodológico no uso de fontes. 
Outro problema que percebemos, é a questão do porte teórico metodológico no trabalho com as evidencias, pois nem sempre há para trabalhos novos ou uma historiografia que contemple os elementos pretendidos pelos autores dos textos. Ou seja, se dinamiza a pesquisa histórica a partir das novas abordagens e temáticas, mas não se acompanha um debate teórico mais profundo. Isto pode resultar em resultados que sejam benéficos, pois se constroem novas perspectivas, por outro lado, há uma dificuldade em buscar referenciais teóricos para as pesquisas e projetos, dificultando a execução dos mesmos. Um problema que deve sempre ser analisado com atenção.

A grande variedade de possibilidades de utilização e revisão dessas fontes é também um fato já estabelecido como se pode perceber ao longo deste texto e das tantas pesquisas publicadas em periódicos e defendidas nas pós-graduações. Isso pode, como mencionado anteriormente abrir dois campos, um no qual se encontram poucos aparatos e outro no qual os desafios estão postos. Aliado a isso, e como é objetivo destacar aqui, que o trabalho do historiador se dá principalmente pelo seu caráter metodológico, aliando-se a ideia de Thompson (1981), a qual o autor evidencia os passos pelo qual o historiador deve reafirmar sua ciência. Demonstrando como e porque a História possui uma lógica própria que mesmo aliando-se a outras áreas do conhecimento, esta ainda mantém prerrogativas teóricas e de método que garantem ao profissional da área fazer suas proposições historiográficas.

Para dar conta destes elementos é importante destacar que a crítica à fonte pode ser um dos possíveis caminhos na construção de uma pesquisa histórica consistente e reconhecida, caminho pelo qual os historiadores vêm traçando seus trabalhos. Os limites das fontes são tão importantes quanto as respostas que possibilitam. Como vimos, os batismos não respondem todos os questionamentos por si só, devem mediante a abrangência das pesquisas se aliarem a outras fontes (OLIVEIRA, 2012).

Os inventários não dão conta da totalidade da sociedade, nem dizem respeito a todas as pessoas, além de tratar de assuntos e dados que são analisados apenas no fim da vida dos indivíduos, o que limita o alcance, mas que com o tratamento correto e a tenção do profissional, as lacunas podem ser preenchidas pelos caminhos do método e de outras fontes. Os viajantes, como é sabido trazem toda sua carga pessoal para seus textos e muitas vezes podem fazer juízos de valor a partir do seu ângulo de visão. Pra isso uma consideração a respeito do pensamento do período estudado e de como se estabelecia aquela sociedade estudada e visitada pelos cronistas pode ser uma saída para esta limitação. Além disso, qualquer uma dessas fontes possuem seus limites e não trazem todas as respostas. O historiador deve sempre se questionar sobre as informações que existem nelas, pois não podemos acreditar em tudo o que está presente nelas.

A importância da iniciação científica é ponto essencial na construção dos trabalhos apresentados ao longo deste texto, e que em sua maioria foram e são desenvolvidos por alunos da graduação que promovem a pesquisa e acabam construindo projetos os quais serão desenvolvidos em programas de pós-graduação resultando em pesquisas consistentes. $\mathrm{O}$ incentivo dos professores em orientarem trabalhos que deem conta das aspirações dos alunos, sejam estes de graduação ou pós -graduação, é fator decisivo em uma perspectiva mais ampla, e que pode ser igualmente proporcional ao bom desempenho e confiança destes no desenvolvimento de suas próprias análises, os casos de Oliveira (2011), Oliveira e Farinatti (2012), Righi e Tomazi (2014), Tomazi, (2015), Minuzzi (2014; 2015) são exemplos que, ao serem confrontados com o desafio do trabalho com as 
fontes, estes autores integrantes do NEXIX puderam gerar suas pesquisas na área de História, buscando explorar pontos de seu interesse e a partir de influencias recentes na historiografia brasileira. Casos semelhantes devem ser encontrados em outros grupos de pesquisa pelo país e esperamos que cada vez mais surjam trabalhos a partir da iniciação científica.
O esforço final de construção deste trabalho é em poder reunir temáticas estudadas diferentemente por pesquisadores que tiveram seu início no Grupo de Estudos do Século XIX, demonstrando como apenas três fontes podem abrir um leque variado tanto no quesito metodologia quanto abordagens. Espera-se que este ensaio possa ajudar jovens pesquisadores que buscam sanar dúvidas a respeito da ciência histórica e indicar caminhos e leituras a respeito destas fontes.

\section{Referências Bibliográficas}

AMARAL, Marise Basso. Histórias de viagem e a produção cultural da natureza: a paisagem do Rio Grande do Sul segundo os viajantes estrangeiros do século XIX. Porto Alegre: Universidade Federal do Rio Grande do Sul, 2003.

BLEIL DE SOUZA, Susana. Fronteira, poder político e articulações comerciais no Brasil Meridional do final do século XIX. Anuário IEHS, v. 23, p. 305-333, 2009.

BOSI, Ecléa. Memória e Sociedade - lembranças de velhos. São Paulo. Companhia das Letras, 1999.

CABREJAS, Laura Leonor. Vida materia en la frontera bonaerense. In: MAYO, Carlos. Vivir en la frontera: la casa, la dieta, la pulpería, la escuela (1770-1870). Buenos Aires, Biblos, 2000.

CAMARGO, José. A contribuição dos cronistas coloniais e missionários para o conhecimento do território brasileiro. In: Mercator - revista de Geografia da UFC. Fortaleza, ano 1, n. 2, 2002.

CEZAR, Temístocles. Entre antigos e modernos: a escrita da História em Chateaubriand: Ensaios sobre historiografia e relatos de viagem. In: Almanaque Braziliense. São Paulo, n. 11, 2010.

CONSTANTINO, Núncia Santoro de. Relatos de viagem como fontes à História. Porto Alegre: EDIPUCRS, 2012.

DREYS, Nicolau. Notícia descritiva da província do Rio Grande de São Pedro do Sul. Porto Alegre. Editora Nova Dimensão, 1990.

DRUMMOND, José Augusto. A História Ambiental: temas, fontes e linhas de pesquisa. Rio de Janeiro: Estudos Históricos, v. 4, n. 8, 1991.

FARINATTI, Luis Augusto Ebling. Construção de séries e micro-análise: notas sobre o tratamento de fontes para a história social. Anos 90 (UFRGS. Impresso), v. 15, p. 57-72, 2008.

Confins Meridionais: famílias de elite e sociedade agrária na fronteira sul do Brasil (1825 - 1865). Santa Maria: Editora da UFSM, 2010.

. A espada e a capela: relações de compadrio dos oficiais de milícia na fronteira meridional do Brasil (18161835). História Unisinos, v. 16, p. 294-306, 2012.

FLECK, Eliane Cristina Deckmann. De terra de ninguém à terra de muitos: Olhares viajantes e imagens fundadoras (dos séculos XVII ao XIX). In: CAMARGO, Fernando; GUTFREIND, Ieda; REICHEL, Heloísa. (Dir.) Colônia. (Coleção História Geral do Rio Grande do Sul). vol. 1. Passo Fundo: Méritos, 2006.

FRAGOSO, João L. R.; PITZER, Renato R. Barões, homens livres pobres e escravos: notas sobre uma fonte múltipla - inventários post mortem. Revista Arrabaldes, Ano 1, n. 2, set./dez. 1988, p. 29-52.

HALBWACHS, Maurice. A Memória Coletiva. São Paulo: Centauro, 2004. 
HAMEISTER, Martha Daisson. O uso dos registros batismais para o estudo de hierarquias sociais no período de vigência da escravidão. In: Regina Célia Lima Xavier. (Org.). Escravidão e Liberdade: Temas, Problemas e Perspectivas de análise. 1. ed. São Paul: Alameda, 2012, p. 97-122.

JERRAM, Leif. Space: a useless category for historical analysis? In: History and Theory, n. 52, 2013.

KURY, Lorelai. Auguste de Saint-Hilaire, viajante exemplar. In: Intellèctus. Rio de Janeiro: Ano 2, n. 3, 2003.

KURY, Lorelai. Viajantes-naturalistas no Brasil oitocentista: experiência, relato e imagem. In: História, Ciências e Saúde. Rio de Janeiro: v. 3, 2001.

LOTT, Mirian Moura. Registros paroquiais: mudanças e permanências - século XIX. In: Anais do II Simpósio Internacional sobre religiões, religiosidades eculturas. Dourados: Editora UFMS, 2006.

MATHEUS, Marcelo. Santos. Dilatadas Paróquias: senhores e escravos na formação da sociedade luso-brasileira (fronteira sul de São Pedro do Rio Grande, início do século XIX). In: XXVII Simpósio Nacional de História, 2013, Natal-RN. Anais do XXVII Simpósio Nacional de História, 2013.

MINUZZI, João Davi Oliveira. Percepções do mundo natural: o pampa na visão de viajantes europeus no início do século XIX. In: XXVIII Simpósio Nacional de História. Lugares dos historiadores: velhos e novos desafios, 2015. Florianópolis: Anais Eletrônicos, 2015.

O pampa sob os pés: visões de Auguste de Saint-Hilaire sobre o pampa em sua obra viagem ao Rio Grande do Sul 1820-1821. Santa Maria: UFSM, 2014.

MOREIRA, Bruno. Os relatos dos viajantes estrangeiros no Brasil oitocentista: possibilidades historiográficas. Ilhéus: Anais do ciclo de estudos históricos da UESC, 2009.

CONSTANTINO, Núncia Santoro de. Relatos de viagem como fontes à História. ed 1. Porto Alegre: Edipucrs, 2012 .

OLIVEIRA, L. R.. Análise Serial de Registros de Batismo da Capela de Alegrete (1820-1844): Possibilidades de Distorção de Dados. In: XXI Mostra de Iniciação Científica - A pesquisa unindo conhecimentos, 2011, Passo Fundo. Anais da XXI Mostra de Iniciação Científica - A pesquisa unindo conhecimentos, 2011.

OLIVEIRA, L. R.; BOTH, A. C.; FARINATTI, L. A. E. . Compadrio, Casamento e Ocupações dos escravos na fronteira sul do Brasil (Alegrete, 1831 - 1850). In: 26 Jornada Acadêmica Integrada, 2011, Santa Maria. Anais $26^{a}$ Jornada Acadêmica Integrada, 2011.

OLIVEIRA, L. R.; FARINATTI, L. A. E. . Relações de compadrio e hierarquização social em um contexto de guerra (Revolução Farroupilha - Alegrete, RS, 1836-1844). In: 27 Jornada Acadêmica Integrada, 2012, Santa Maria. Anais $27^{a}$ Jornada Acadêmica Integrada, 2012.

OLSEN, Bjørnar. Material culture after text: re-membering things. In: Norwegian Archaeological Review, v. 36, n. 2, 2003, p. 87-104.

PEIXOTO, Dilson. Do gado as matas: O impacto ambiental no rio grande do sul a partir da memória de viajantes (1808-1822). Santa Maria: Unifra, 2010.

. Indícios da alteração ambiental nas crônicas de três viajantes (Rio Grande do Sul, 1808-1827). Revista Eletrônica História em Reflexão (UFGD), v. 9, p. 1-21, 2015.

PRATT, Mary Louise. Os olhos do império: relatos de viagem e transculturação. Bauru: Edusc, 1999.

REVEL, Jacques. Micro-história, macro-história: o que as variações de escala ajudam a pensar em um mundo globalizado. Tradução Anne-Marie Milon de Oliveira. Revista Brasileira de educação, v. 15, n. 45, set. 2010.

RIBEIRO. Max Roberto Pereira. Estratégias indígenas na fronteira meridional: os guaranis missioneiros após a conquista lusitana (Rio Grande de São Pedro, 1801-1834). Rio Grande do Sul, Dissertação (Mestrado), UFRGS, 2013. 
RIGHI, K. S. ; TOMAZI, T. G.. Revisitando registros batismais da Capela de Alegrete, 1821-1834: as idades dos batizandos e sua relação com as práticas católicas. Oficina do Historiador, v. 1, p. 1733-1746, 2014.

SCHAMA, Simon. Paisagem e Memória. São Paulo: Companhia das Letras, 1996.

SCHWARTSMANN, Leonor Carolina Baptista Entre a mobilidade e as inovações: a presença de médicos italianos no Rio Grande do Sul (1901-1938). Porto Alegre, Tese (Doutorado) em História, PUCRS- Porto Alegre, 2013. THOMPSON, Edward. Intervalo: A lógica Histórica. In: A miséria da Teoria. Rio de Janeiro, Zahar, 1981.

THOMPSON FLORES, Mariana F. C., Contrabando e contrabandistas na fronteira oeste do Rio Grande do Sul (1851-1864). Rio Grande do Sul, Dissertação (Mestrado) - Programa de Pós-Graduação em História - Universidade Federal do Rio Grande do Sul, Rio Grande do Sul, 2007.

TOMAZI, T. G.. Entre uma Idealização europeia e a realidade Platina: Padrão Civilizacional, fronteira e costumes cotidianos, Alegrete, 1846 à 1886. In: VIANNA, Marcelo et al. (Org.). O historiador e as novas tecnologias: reunião de artigos do II Encontro de Pesquisas Históricas - PUCRS. 1. ed. Porto Alegre: Memorial do Ministério Público do Rio Grande do Sul, 2015, p. 1803-1814.

. Padrão Civilizacional na Fronteira meridional do Brasil, Alegrete (1846-1886). In: III Congresso Internacional de História Regional, 2015, Passo Fundo/RS. Anais Eletrônicos do III Congresso Internacional de História Regional (2015). Passo Fundo/RS, 2015.

VARGAS, J. M. Pelas margens o Atlântico: Um estudo sobre elites locais regionais no Brasil a partir das famílias proprietárias de charqueadas em Pelotas, Rio Grande do Sul (século XIX). Tese (Doutorado em História), UFRJ, 2013.

VOLKMER, Márcia Solange. O comércio na Fronteira Oeste do Rio Grande do Sul na segunda metade do século XIX. In: XXVII Simpósio Nacional de História, 2013, Natal. Anais Eletrônicos, 2013. 